\title{
Characterization of Escherichia coli adenylate cyclase mutants with modified regulation
}

\author{
Martine Crasnier* and Antoine Danchin \\ Institut Pasteur, Unité de Régulation de l'Expression Génétique, 28 rue du Dr Roux, 75724 Paris cedex 15, France
}

(Received 28 March 1990; revised 4 June 1990; accepted 8 June 1990)

\begin{abstract}
In Escherichia coli there is a large increase of cAMP synthesis in crp strains, which are deficient in the catabolite gene activator protein. In this work it was shown that this increase in cAMP synthesis does not occur in crp crr strains, deficient in both the catabolite gene activator protein and enzymeIII-glucose, a component of the phosphotransferase system. It was also shown that the other components of the phosphotransferase system are required to obtain the increase of cAMP synthesis in a crp background. Adenylate cyclase mutants were obtained, by random mutagenesis, which had partial adenylate cyclase activity but which did not exhibit increased levels of cAMP in a crp background. For three mutants the mutation was identified as a single point mutation. This allowed the identification of residues arginine 188, aspartic acid 414 and glycine 463 which could be involved in the catabolite gene activator protein dependent activation process.
\end{abstract}

\section{Introduction}

Transcriptional regulation by cAMP in Escherichia coli is mediated by a cAMP receptor protein named catabolite gene activator protein (CAP) (Zubay et al., 1970). cAMP binds to CAP, converting it from an inactive form to one that can activate transcription. The concentration of cAMP required to obtain half-maximum binding of CAP-cAMP to a particular DNA-binding site varies considerably (Kolb et al., 1983; Berg \& Von Hippel, 1988), suggesting a hierarchy at the transcriptional level (Alper \& Ames, 1978). However, despite the established regulatory role of CAMP, the mechanism by which adenylate cyclase (AC) activity is regulated is not yet understood. In the presence of glucose, enzymeIIIglucose, a component of the phosphotransferase system (PTS), regulates uptake of non-PTS sugars (inducer exclusion: Magasanik, 1970) and AC activity. The model proposed for the regulation of $\mathrm{AC}$ was based upon genetic experiments which suggested that the phosphorylated form of enzymelli-glucose was an activator of AC (Feucht \& Saier, 1980; Postma et al., 1981). When glucose transport takes place, the intracellular concentration of phosphorylated enzymeIII-glucose decreases and correlates with a decrease in intracellular cAMP concentration. Several mutants of the structural gene for enzymeIIl-glucose have been isolated which have lost

\footnotetext{
Abbreviations: AC, adenylate cyclase; CAP, catabolite gene activa-
} tor protein; PTS, phosphotransferase system. inducer exclusion but which are still subject to glucosemediated inhibition of AC (Feucht \& Saier, 1980).

It has been known for nearly 20 years that the production of cAMP is increased 20- to 100-fold in $\mathrm{crp}$ mutants (Potter et al., 1974; Fraser \& Yamazaki, 1978). This increase could not be accounted for by an elevated level of expression of AC (Mori \& Aiba, 1985; Roy et al., 1988 ) and it was suggested that CAP could regulate the activity of AC (Joseph et al., 1982; Dobrogosz et al., 1983). However, the mechanism of regulation has not yet been elucidated. In the present work, we investigated the role of enzymeIII-glucose in the increase of cAMP synthesis in $c r p$ strains. We also describe a class of $E$. coli $\mathrm{AC}$ structural gene (cya) mutants which can still produce cAMP but which produce the same level of cAMP in $c r p$ and $c r p^{+}$strains.

\section{Methods}

Bacterial strains. The strains used in this work were $E$. coli $\mathrm{K} 12$ derivatives (Table 1). Growth media were either LB or minimal medium M63 (Miller, 1972) supplemented with the required amino acids $(1 \mathrm{~mm})$, thiamin $\left(5 \mu \mathrm{g} \mathrm{m}^{-1}\right)$ and different carbon sources $(0.4 \%$, $\mathrm{w} / \mathrm{v})$. Transductions using Plvir were done as described by Miller (1972).

cAMP assays. The secretion of cAMP by bacteria was assessed by using strain TP610A as an indicator bacterium. Strain TP610A is a spontaneous mutant of strain TP610 which produces red colonies on $1 \%(w / v)$ maltose MacConkey agar when supplemented with low levels of cAMP $(15 \mu \mathrm{M}$ instead of the $200-500 \mu \mathrm{M}$ required by most cya 
Table 1. E. coli strains and plasmids

\begin{tabular}{|c|c|c|}
\hline $\begin{array}{c}\text { Strain } \\
\text { or plasmid }\end{array}$ & Genotype & Origin \\
\hline \multicolumn{3}{|l|}{ E. coli } \\
\hline TP2503 & $\begin{array}{l}\mathrm{F}^{-} x y l \text { argHI ilvA } \\
\mathrm{F}^{-} x y l \text { argHI } \Delta l a c X 74 \text { aroB ilvA }\end{array}$ & $\begin{array}{l}\text { De Reuse \& Danchin (1988) } \\
\text { Roy et al. }(1983 b)\end{array}$ \\
\hline $\begin{array}{l}\text { TP2111 } \\
\text { TP2006 }\end{array}$ & $\begin{array}{l}\mathrm{F}^{-} \text {xyl argHI } \Delta l a c X 74 \text { aroB ilvA } \\
\mathrm{F}^{-} \text {xyl } \Delta c y a \Delta \text { lacX74 glp8306 }\end{array}$ & $\begin{array}{l}\text { Roy et al. (1983b) } \\
\text { Roy \& Danchin (1982) }\end{array}$ \\
\hline $\begin{array}{l}\text { TP2006 } \\
\text { TP610 }\end{array}$ & $\mathrm{F}^{-}$thi-1 thr-1 leuB6 pro lacY1 tonA21 & Hedegaard \& Danchin (1985) \\
\hline & $\begin{array}{l}\text { supE } 44 \lambda-h s d R \text { hsdM recBC lop-11 lig } \\
\text { cya- } 610\end{array}$ & \\
\hline TP2010 & $\begin{array}{l}\mathrm{F}^{-} x y l \Delta c y a \text { argH1 } \Delta l a c X 74 \text { recA } \\
\text { srl::Tn10 }\end{array}$ & Roy \& Danchin (1981) \\
\hline TP9500* & $\mathrm{F}^{-}$xyl $\Delta c y a$ argHI & $\mathrm{TP} 2503 \times \mathrm{P} 1\left(\mathrm{TP} 2006 i l v^{+}\right)$ \\
\hline TP2139 & F $^{-}$xyl $\Delta c r p-39 \Delta l a c X 74$ argHI ilvA & Roy et al. $(1983 b)$ \\
\hline TP2339 & $\mathrm{F}^{-}$xyl $\Delta$ cya $\Delta c r p-39 \Delta$ lacX74 argHl & Roy et al. $(1983 b)$ \\
\hline TP2862 & $\mathrm{F}^{-}$xyl argHI aroB ilvA $\Delta c r r \mathrm{Km}^{\mathrm{r}}$ & Lévy et al. (1990) \\
\hline TP2811 & $\mathrm{TP} 2111 \Delta(p t s H$ ptsI crr $) \mathrm{Km}^{\mathrm{r}}$ & Lévy et al. (1990) \\
\hline TP9510* & $\mathrm{F}^{-}$xyl argHl ilvA $\Delta c r p-39 \Delta c r r \mathrm{Km}^{\mathrm{r}}$ & TP2862 × P1 $\left(\right.$ TP2139 aro $\left.^{+}\right)$ \\
\hline TP9511* & $\begin{array}{l}\mathrm{F}^{-} \text {xyl argH1 ilvA } \Delta l a c X 74 \Delta c r p-39 \\
\Delta(\text { ptsH ptsI crr }) \mathrm{Km}^{\mathrm{r}}\end{array}$ & TP2139 × P1(TP2811 Kmr) \\
\hline \multicolumn{3}{|l|}{ Plasmids } \\
\hline pDIA4705 & $\begin{array}{l}\text { Derivative of pBR } 322 \text { containing the } \\
\text { crr gene, } \mathrm{Ap}^{\mathrm{r}}\end{array}$ & G. Q. Zeng, unpublished \\
\hline pSa206 & Low-copy-number plasmid, $\mathrm{Km}^{\mathrm{r}}$ & Close et al. (1984) \\
\hline pDIA100 & $\begin{array}{l}\text { Derivative of } \mathrm{pBR} 322 \text { containing the } \\
\text { cya gene, } \mathrm{Ap}^{\mathrm{r}}\end{array}$ & Roy \& Danchin (1982) \\
\hline pDIA1900* & $\begin{array}{l}\text { Derivative of pSa206 containing the } \\
\text { cya gene, } \mathrm{Km}^{\mathrm{r}}\end{array}$ & \\
\hline
\end{tabular}

* Bacterial strains and plasmid derived during this work.

strains). A drop of an overnight culture of the strain to be analysed was plated on a lawn of strain TP610A and the plate was then incubated at $37^{\circ} \mathrm{C}$ overnight. Strains secreting significant levels of cAMP produced a red halo around the culture drop due to the fermentation of maltose by strain TP610A.

cAMP production was quantified by a radioimmunological assay (Guidi-Rontani et al., 1981) with cultures grown in minimal medium M63. The amount of cAMP was expressed as pmol per mg dry weight of bacteria, including intracellular cAMP and cAMP secreted into the culture medium. Assays were carried out with bacterial suspensions heated for $5 \mathrm{~min}$ at $100^{\circ} \mathrm{C}$.

In vitro mutagenesis. In vitro mutagenesis with hydroxylamine was performed overnight as described by Manayan et al. (1988). After extensive dialysis, the mutagenized plasmid was used to transform the appropriate host cell.

$\beta$-Galactosidase assay. Expression of the lac operon was measured by determining $\beta$-galactosidase activity (Pardee et al., 1959) of bacteria during exponential growth in minimal medium M63. When glucose 6phosphate was used as the carbon source, isopropyl $\beta$-D-thiogalactoside was added at the concentration of $0.5 \mathrm{mM}$. A unit of $\beta$-galactosidase activity was defined as the amount of enzyme that hydrolysed $1 \mathrm{nmol} \sigma$ nitrophenyl $\beta$-D-galactoside $\min ^{-1}$ under standard conditions (Pardee et al., 1959).

Analysis of plasmid-encoded proteins. Minicells of strain AR 1062 were purified as described by Rambach \& Hogness (1977). Labelled proteins were fractionated by polyacrylamide gel electrophoresis under denaturing conditions (Laemmli, 1970).

DNA sequence analysis. The sequencing strategy involved cloning Bam HI-HpaI fragments $(1.4 \mathrm{~kb})$ of different mutated AC (cya) genes into compatible sites of M13mp18 and M13mp19 (Yanisch-Perron et al., 1985). Single-stranded M13 templates were sequenced by the chaintermination method (Sanger et al., 1977) using the Sequenase version 2.0 DNA sequencing kit from United States Biochemical Corporation.

\section{Results}

Increased cAMP production in a crp strain requires phosphorylated enzymeIII-glucose

Isogenic strains deficient in CAP $(\Delta c r p-39)$, in enzymeIII-glucose $(\Delta c r r)$ or in both CAP and enzymeIII-glucose were analysed for CAMP secretion on maltose MacConkey plates (see Methods and Fig. 1). Only the strain deficient in CAP alone secreted sufficient cAMP to produce red colonies of the indicator strain TP610A. Transformation of the strain deficient in both CAP and enzymeIII-glucose with pDIA4705, a derivative of pBR322 containing a functional $\mathrm{cr}$ gene, restored the red halo due to the excretion of cAMP (Fig. 1). This result indicated that the $\mathrm{crr}$ gene product is required for the production of high levels of cAMP in strains deficient in CAP.

The same experiment was carried out with strain TP9511, which is deficient in CAP and in enzymeI, Hpr and enzymeIII-glucose (the components of the PTS for 


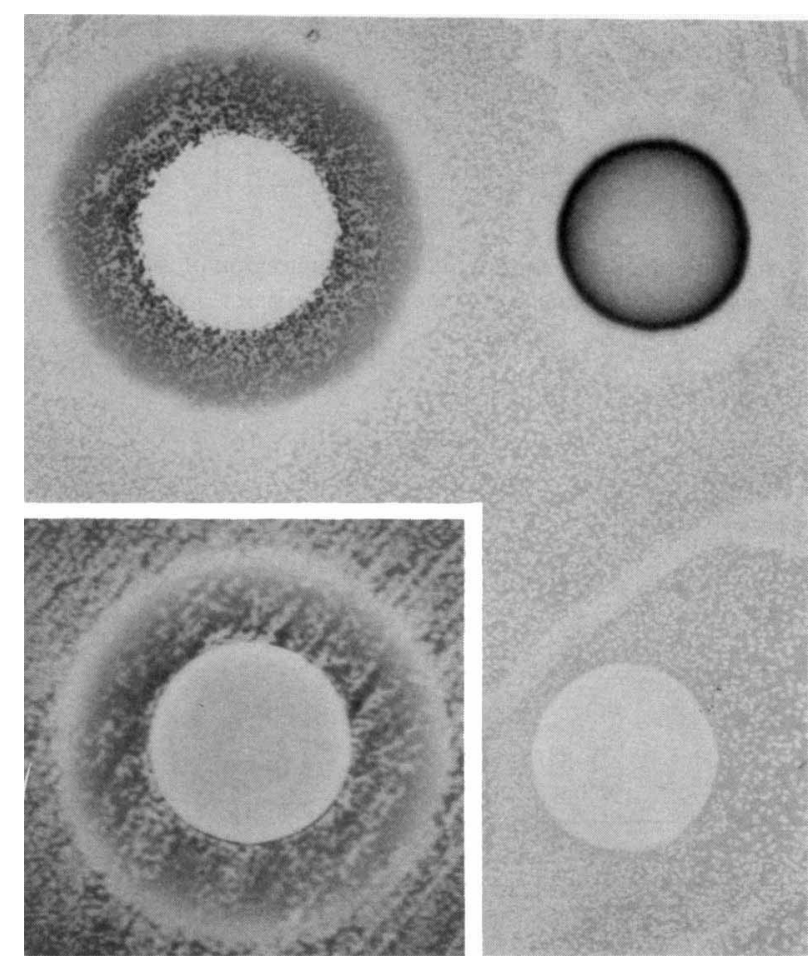

Fig. 1. Secretion of cAMP by different isogenic strains. Top left, strain TP2139 ( $\Delta c r p)$; top right, strain TP2862 ( $\Delta c r r)$; bottom right, strain TP9510 ( $\Delta c r p \Delta c r r)$. Inset, bottom left, strain TP9510 containing pDIA4705.

glucose transport). Even after transformation with pDIA4705 a red halo was not observed (data not shown). The phosphorylation of enzymeIII-glucose by the other components of the PTS is therefore necessary for the overproduction of cAMP in strains deficient in CAP.

In addition, total cAMP was determined after growth of strains in medium with pyruvate as sole carbon source. Total cAMP per mg dry weight of bacteria was constant during the exponential phase of growth. Mean values of three independent experiments were (pmol per mg dry weight of bacteria): 3000 for the wild-type strain TP2111, 50000 for the $\Delta c r p$ strain TP2139, 150 for the $\Delta c r r$ strain TP2862 and 200 for the $\Delta c r p \Delta c r$ strain TP9510. Thus in the $\Delta c r p$ strain, cAMP per mg dry weight of bacteria was increased about 20-fold as compared to the wild-type, but in the $\Delta c r p \Delta c r r$ strain it was very similar to that of the $\Delta c r r$ strain. These results were in agreement with the visual observations on MacConkey plates. The lower level of cAMP observed for the $\Delta c r r$ strain compared to the wild-type strain suggests that enzymeIII-glucose activates $\mathrm{AC}$.

\section{Screening and characterization of $E$. coli AC mutants}

The $4.3 \mathrm{~kb}$ EcoRI-SalI fragment of pDIA100, a derivative of pBR322 containing the cya gene (Roy \& Danchin, 1982), was inserted into EcoRI + SalI-digested pSa206, a low-copy-number plasmid (Close et al., 1984), to give pDIA1900 (Fig. 2). When the $\Delta c y a$ strain TP2010 was transformed with derivatives of pDIA 1900 obtained by partial digestion with $B c l I$, clones with an intermediate phenotype ( $\mathrm{Cya}^{+/-}$, white colonies with a red centre) were obtained. Plasmids from such clones were invariably deleted from $B c l(2)$ to $B c l I(3)$ or $B c l$ (4) (see Fig. 2 ). This result was not surprising, as different truncated forms at the carboxy-terminal end of $\mathrm{AC}$ have been shown to retain AC activity (Roy et al., 1983a), but it showed that it was possible to screen AC mutants with a lower activity than the wild-type AC on MacConkey plates. The fact that the level of cAMP in a $\Delta c r r$ strain was lower than that of a wild-type strain (see above) indicated that such mutants could be affected in the activation process mediated by enzymeIII-glucose.

pDIA1900 was mutagenized with hydroxylamine and then used to transform a $\Delta c y a$ strain (TP2010). Cya ${ }^{+/-}$ clones appeared at a frequency of $24 / 1000$. Four such clones (TP2010 containing pDIA1901, pDIA1902, pDIA1903 or pDIA1904) and a Cya ${ }^{-}$control (TP2010 containing pDIA1905) were isolated. TP2010 containing pDIA1901 was temperature-sensitive for the Cya phenotype, but TP2010 containing pDIA1902, pDIA1903 or pDIA1904 was not.

In order to compare the activities of the different proteins expressed from the mutagenized plasmids, strain TP9500 ( $\triangle c y a)$ was transformed with pDIA1900, pDIA1901, pDIA1902, pDIA1903 or pDIA1904, and $\beta$ galactosidase activity produced with lactose or glucose 6phosphate as sole carbon source was measured (Table 2). With TP9500 containing pDIA1901, pDIA1902 or pDIA1903, $\beta$-galactosidase activities were lower than that obtained with the strain containing the wild-type plasmid pDIA1900, but with TP9500 containing pDIA 1904, $\beta$-galactosidase activity was very similar to that of TP9500 containing pDIA1900. With glucose 6phosphate as carbon source, $\beta$-galactosidase activities were very low, as already reported by others for wild-type strains (Epstein et al., 1975). The data in Table 2 show that the levels of $\beta$-galactosidase measured in lactose compared to glucose 6-phosphate medium were higher in TP9500 containing pDIA1901, pDIA1902 or pDIA1903 (about 4-fold) than in TP9500 containing pDIA1900 or pDIA1904 (about 1.5-fold). In order to substantiate those results, the variations of cAMP per $\mathrm{mg}$ dry weight of bacteria in cells grown with lactose or glucose 6phosphate were measured (Table 2 ); the results correlated with the variations in $\beta$-galactosidase levels. 


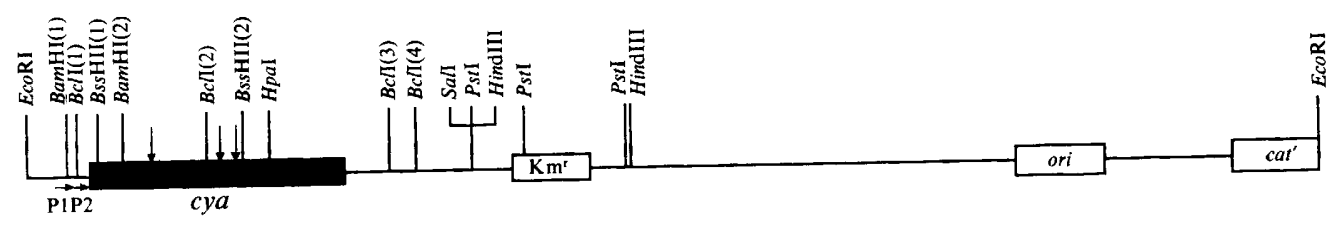

Fig. 2. Partial restriction map of plasmid pDIA1900, containing the cya gene. The black box represents the coding region of the cya gene. Location of the promoters is represented by $\mathrm{P} 1$ and $\mathrm{P} 2$. The vertical arrows indicate the location of the mutations described in this work. cat' indicates a truncated chloramphenicol acetyltransferase gene.

Table 2. $\beta$-Galactosidase activity and cAMP levels in $\Delta$ cya strains containing mutagenized plasmids

\begin{tabular}{|c|c|c|c|c|}
\hline \multirow{2}{*}{$\begin{array}{l}\text { Strain TP9500 } \\
\left(\triangle c y a, \text { lac }^{+}\right) \\
\text {containing: }\end{array}$} & \multicolumn{2}{|c|}{$\begin{array}{c}\beta \text {-Galactosidase activity } \\
{[U(\mathrm{mg} \text { dry wt of }} \\
\left.\text { bacteria })^{-1}\right] \text { with: }\end{array}$} & \multicolumn{2}{|c|}{$\begin{array}{c}\text { Total cAMP* } \\
\text { [pmol (mg dry wt } \\
\text { of bacteria) }{ }^{-1} \text { ] with: }\end{array}$} \\
\hline & Lactose & Glc 6-P & Lactose & Glc 6-P \\
\hline pDIA1900 (WT) & 2600 & 1800 & $230( \pm 30)$ & $130( \pm 8)$ \\
\hline pDIA1901 & 1210 & 360 & $50( \pm 5)$ & $20( \pm 1)$ \\
\hline pDIA 1902 & 1900 & 490 & $85( \pm 7)$ & $35( \pm 2)$ \\
\hline pDIA1903 & 1570 & 340 & $65( \pm 7)$ & $20( \pm 5)$ \\
\hline pDIA1904 & 2440 & 1460 & $180( \pm 12)$ & $100( \pm 8)$ \\
\hline
\end{tabular}

* Means \pm SEM of three determinations.

Proteins expressed from mutagenized plasmids were characterized by minicell experiments in order to visualize possible truncated forms of the mutant proteins. The $4.3 \mathrm{~kb}$ EcoRI-SalI fragment of pDIA1901, pDIA1902, pDIA1903, pDIA1904 or pDIA1905 was inserted in pBR322 digested with EcoRI and $S a l I$ and the corresponding plasmids were used to transform the minicell-producing strain AR1062. Plasmid-encoded proteins, labelled with $\left[{ }^{35}\right.$ S $]$ methionine, were analysed by polyacrylamide gel electrophoresis (Fig. 3). The mutant proteins expressed from pDIA1902, pDIA1903 and pDIA1904 (Fig. 3, lanes 3, 4 and 5) were similar in size to the wild-type AC (about $97 \mathrm{kDa}$, lane 6). One truncated form of about $52 \mathrm{kDa}$ was expressed from pDIA1901 (lane 1). In the case of pDIA1905, the absence of protein on the gel (lane 2) was in agreement with the fact that a $\triangle c y a$ strain containing this plasmid remained $\mathrm{Cya}^{-}$(see above).

In order to locate the mutations, the BamHI(1)BamHI(2) fragment (which contains the promoter region) or the EcoRI-HpaI fragment (which contains the catalytic site) or the HpaI-SalI fragment (see pDIA1900, Fig. 2) of each mutated plasmid was subcloned in pDIA1900, deleted for the corresponding fragment. The plasmids thus obtained were used to transform strain TP2339, which is deficient in both CAP and AC. The secretion of cAMP by the clones thus obtained was assessed using the indicator strain and compared to the secretion obtained with the wild-type plasmid. This allowed the determination of the fragment responsible for the mutated phenotype. For pDIA1902, pDIA1903 and pDIA1904, the mutations were located in the Bam HI-HpaI fragment and thus the nucleotide sequences of the BamHI(2)-HpaI fragments of pDIA1902, pDIA1903 and pDIA1904 were determined. The mutations which were found corresponded to those usually obtained with hydroxylamine, which produces G.C $\rightarrow$ A .T transitions (Phillips \& Brown, 1967). In each case, a single base change had occurred, leading to a single amino acid substitution. Amino acid residue 414 of the protein encoded by pDIA 1902 was changed from aspartic acid to asparagine (Fig. $4 a$ ), amino acid residue 188 of the protein encoded by pDIA1903 was changed from arginine to histidine (Fig. $4 b$ ) and amino acid residue 463 of the protein encoded by pDIA1904 was changed from glycine to aspartic acid (Fig. 4c). The vertical arrows in Fig. 2 indicate the location of the different mutations. 


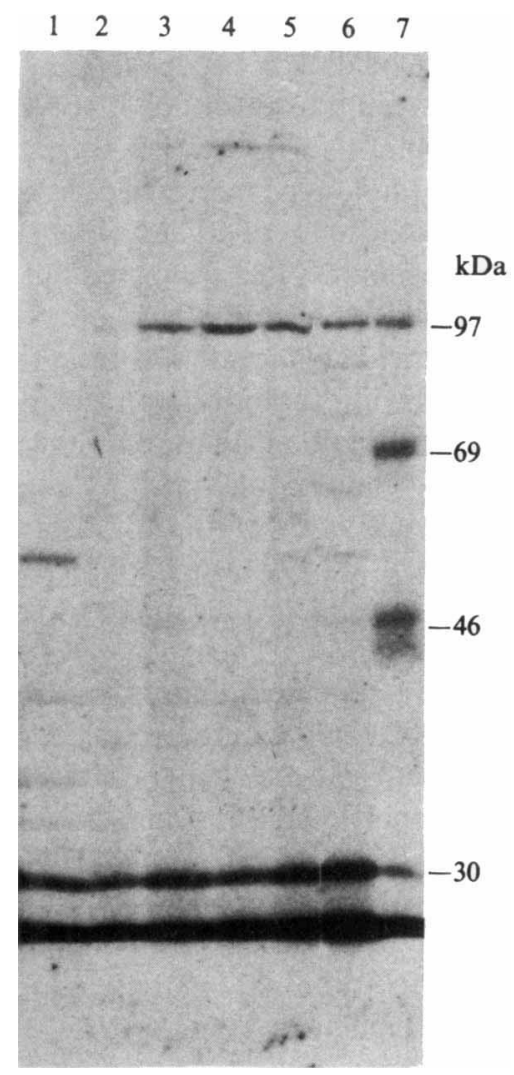

Fig. 3. Polyacrylamide gel electrophoresis of plasmid-encoded proteins expressed in minicells of strain AR 1062. Lane 1, pDIA1901; lane 2, pDIA1905; lane 3, pDIA1902; lane 4, pDIA1903; lane 5, pDIA1904; lane 6, pDIA1900 (wild-type), lane 7, molecular mass markers.

(a)

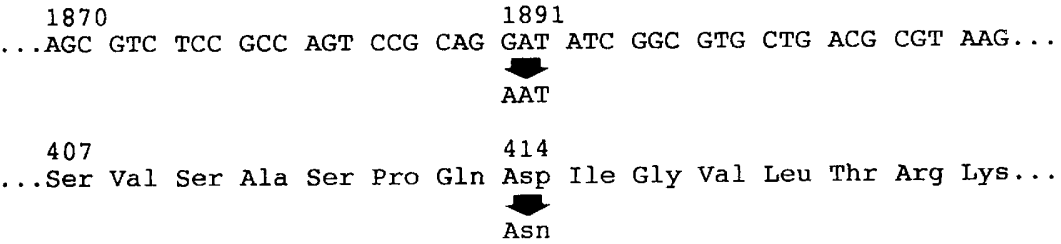

(b)

...CTG CTG CTT GAC GAa TTT TAT $\underbrace{1213}_{\text {CAT }}$ ACC GCC GTG CGT. CTC GCC GGT...

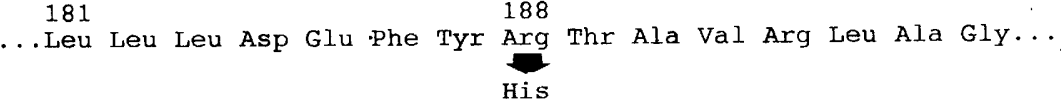

(c)

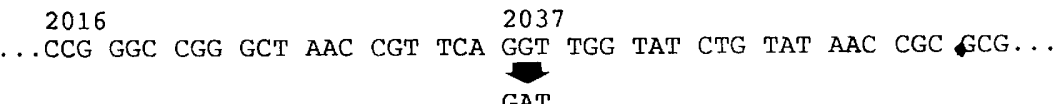
...Pro Gly Arg Ala Asn Arg Ser Gly Trp Tyr Leu Tyr Asn Arg Ala...

\section{Cyclases encoded by mutagenized plasmids do not produce high levels of cAMP in crp strains}

The secretion of cAMP by strain TP2339, which is deficient in both CAP and AC, containing pDIA1900, pDIA1901, pDIA1902, pDIA1903 or pDIA1904 was assessed using strain TP610A as indicator as before. Strain TP2339 containing pDIA1900 produced a red halo on the plates but TP2339 containing pDIA1901, pDIA1902 or pDIA1903 did not. In the case of strain TP2339 containing pDIA1904, enough cAMP was secreted to allow the production of a small halo.

Total cAMP assays of the same strains grown on pyruvate were performed and the levels of cAMP obtained were compared to those obtained with strain TP9500, which is deficient in AC, containing the same plasmids (Fig. 5). When TP9500 was used as the host cell, the levels of cAMP obtained with the different mutated plasmids were lower than that obtained with pDIA1900 (about a 12-fold, 4-fold, 10-fold and 2-fold decrease with pDIA1901, pDIA1902, pDIA1903 and pDIA1904 respectively). The higher levels of cAMP observed for wild-type AC in a crp background were not obtained with AC encoded by pDIA1901, pDIA1902 or pDIA1903 (Fig. 5). In the case of pDIA1902, the crp strain had a lower level of cAMP than the $c r p^{+}$strain; this was surprising and remains to be explained. In the case of pDIA1904, total cAMP was increased 5-fold (instead of 25 -fold for wild-type $A C$ ), a result in agreement with the cAMP secretion observed on MacConkey plates. 


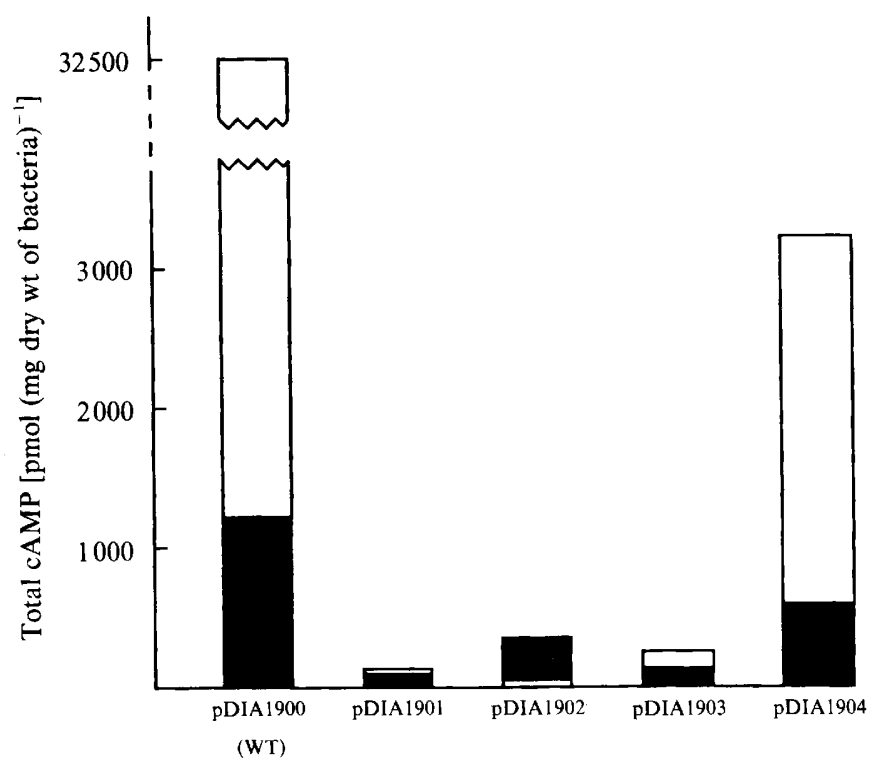

Fig. 5. Comparison of the levels of cAMP in strain TP9500 ( $\Delta c y a ; \mathbf{D})$ and in strain TP2339 ( $\Delta$ cya $\Delta c r p ; \square)$, both transformed with the different mutated plasmids.

\section{Discussion}

Strains deficient in CAP overproduce cAMP but the molecular mechanism underlying the increase in cAMP is not known. We have shown that it requires enzymeIIIglucose. The increase of cAMP in $c r p$ strains was also shown to be dependent on the presence of enzymeI and $\mathrm{Hpr}$, the other components of the PTS. This result indicates that the phosphorylated form of enzymeIIIglucose is involved in the CAP-dependent activation process. To explain the decrease of cAMP synthesis in wild-type strains of Salmonella typhimurium grown on glucose, Postma (1982) proposed a model where phosphorylated enzymeIII-glucose was described as an activator of AC. By analogy with this model the simplest hypothesis to explain the high level of cAMP in $c r p$ strains compared to wild-type strains would be that phosphorylated enzymellI-glucose activates $\mathrm{AC}$ in the absence of CAP. CAP (or an effector whose transcription will be under CAP-cAMP control) would interfere with the activation process by interacting with phosphorylated enzymellI-glucose. An alternative hypothesis would be that CAP interacts with $\mathrm{AC}$, preventing the activation of AC by phosphorylated enzymeIII-glucose. A direct interaction between CAP and AC leading to an inhibition of AC activity has already been proposed (Dobrogosz et al., 1983). However, such an inhibition of AC by CAP seems unlikely under our experimental conditions since the levels of cAMP in $\mathrm{crr}$ strains and in crr $\operatorname{crp}$ strains were very similar.

The mechanism by which the cAMP receptor protein prevents the activation of $\mathrm{AC}$ in wild-type strains remains to be elucidated, especially as regards the interactions between the effectors involved. For this purpose, four mutant forms of $\mathrm{AC}$ were obtained by random mutagenesis and characterized. Minicell experiments showed that one of them (that encoded by pDIA1901) corresponded to a truncated but active form of AC which produced a similar level of cAMP in wildtype and $c r p$ strains. This result was in agreement with the previous observation that different truncated forms at the carboxy-terminal end retained some $\mathrm{AC}$ activity but had lost the regulation mediated by glucose (Roy $e t$ al., 1983a). The activities of the cyclases encoded by pDIA1902 and by pDIA1903 were not increased in a $c r p$ background and their molecular masses were similar to that of the wild-type AC. Their genes were sequenced and, in both cases, a single mutation was found. In the case of pDIA1902, the mutation was located about $100 \mathrm{bp}$ downstream of the $B c / \mathrm{I}(2)$ site (see Fig. 2), indicating that aspartic acid residue 414 (changed into asparagine) may be required for the CAP-dependent activation process. Based upon gene deletion experiments it has been proposed that AC is composed of two domains: the amino-terminal catalytic domain and the carboxy-terminal regulatory domain (Roy et al., 1983a). Thus Asp-414 (aspartic acid is often found on the surface of proteins) could play a role either in the contact between the two domains or in an interaction with enzymeIII-glucose. In the case of pDIA1903, the mutation was mapped to a $B c l$ fragment which deletion studies showed to be essential for AC activity (see Fig. 2). This mutation was located in a region of the DNA which may code for the active site (or part of the active site) of $\mathrm{AC}$, as shown by the fact that a 200 bp deletion in this region produces a $\mathrm{Cya}^{-}$phenotype (Brickman et al., 1973; Glaser et al., 1989). In this mutant, arginine residue 188 was changed to histidine. A change from arginine to histidine is a conservative change (Barker \& Dayhoff, 1972) and the fact that such a change caused a mutant phenotype suggests that Arg-188 is an important residue.

The AC protein encoded by pDIA1904 showed a 2fold decrease in cAMP synthesis as compared to wildtype $\mathrm{AC}$ in a $c r p^{+}$background and a 10 -fold decrease in a crp background (with pyruvate as sole carbon source). Therefore glycine residue 463 (which was changed to aspartic acid in this mutant) may not be directly related to the regulation mediated by CAP in a wild-type strain.

Finally, it must be emphasized that Asp-414 and Arg188 seem to be essential for the CAP-dependent activation process. Neither mutation completely abolished AC activity but both inhibited the increase in activity normally observed in $c r p$ strains. If this increase is indeed dependent upon a direct interaction between 
$\mathrm{AC}$ and enzymelli-glucose, mutants with higher AC activity than the wild-type should be obtained even in $\mathrm{crr}$ strains.

We are very grateful to Agnès Ullmann for her valuable comments and suggestions during the writing of the manuscript. We thank Bernard Lubochinsky for critical reading of the manuscript. We also thank Francis Biville for stimulating discussions, Odile Sismeiro and Valerie Dumay for help during the sequencing, Philippe Lejeune for setting up the 'cAMP assay' on piates and Bernadette George for expert typing. pDIA4705 was kindly provided by G. Q. Zeng. This work was supported by grants from the CNRS (UA 1129) and from the Pasteur Institute.

\section{References}

ALPER, M. D. \& AMES, B. N. (1978). Transport of antibiotics and metabolite analogs by systems under cAMP control: positive selection of Salmonella typhimurium cya and crp mutants. Journal of Bacteriology 133, 149-157.

BARKer, W. C. \& Dayhoff, M. O. (1972). Detecting distant relationships: computer methods and results. In Atlas of Protein Sequence and Structure, pp. 101-110. Edited by M. O. Dayhoff Washington, DC: National Bomedical Research Foundation.

BERG, O. G. \& VON HIPPEL, P. H. (1988). Selection of DNA binding sites by regulatory proteins. II. The binding specificity of cyclic AMP receptor protein to recognition sites. Journal of Molecular Biology 200, 709-723.

BrickMan, E., Soll, L. \& BECKwITH, J. (1973). Genetic characterization of mutations which affect catabolite-sensitive operons in Escherichia coli, including deletions of the gene for adenyl cyclase. Journal of Bacteriology 116, 582-587.

Close, T. J., Zaitlin, D. \& Kado, C. I. (1984). Design and development of amplifiable broad-host-range cloning vectors: analysis of the vir region of Agrobacterium tumefaciens plasmid pTIC58. Plasmid 12, 111-118.

DE REUSE, H. \& DANCHIN, A. (1988). The pts H, ptsI and crr genes of the Escherichia coli phosphoenolpyruvate-dependent phosphotransferase system: a complex operon with several modes of transcription. Journal of Bacteriology 170, 3827-3837.

Dobrogosz, W. J., Hall, G. W., Sherba, D. K., Silva, D. O., HARMAN, J. G. \& MELTON, T. (1983). Regulatory interactions among the cya, crp and pts gene products in Salmonella typhimurium. Molecular and General Genetics 192, 477-486.

Epstein, W., Rothman-Denes, L. B. \& Hesse, J. (1975). Adenosine $3^{\prime}, 5^{\prime}$-cyclic monophosphate as mediator of catabolite repression in Escherichia coli. Proceedings of the National Academy of Sciences of the United States of America 72, 2300-2304.

FeUCHT, B. U. \& SAIER, M. H., JR (1980). Fine control of adenylate cyclase by the phosphoenolpyruvate:sugar phosphotransferase systems in Escherichia coli and Salmonella typhimurium. Journal of Bacteriology 141, 603-610.

Fraser, A. D. E. \& Yamazaki, H. (1978). Construction of an Escherichia coli strain which excretes abnormally large amounts of adenosine $3^{\prime}-5^{\prime}$ cyclic monophosphate. Canadian Journal of Microbiology 24, 1423-1425.

Glaser, P., RoY, A. \& Danchin, A. (1989). Molecular characterization of two cya mutations, cya-854 and cya R1. Journal of Bacteriology 171, 5176-5178

Guidi-Rontani, C., Danchin, A. \& Ullmann, A. (1981). Isolation and characterization of an Escherichia coli mutant affected in the regulation of adenylate cyclase. Journal of Bacteriology 148, 753-761.

HEDEgAARD, L. \& DANCHIN, A. (1985). The cya gene region of Erwinia chrysanthemi B374: organisation and gene products. Molecular and General Genetics 201, 38-42.

JosePh, E., Bernsley, C., Guiso, N. \& Ullmann, A. (1982). Multiple regulation of the activity of adenylate cyclase in Escherichia coli. Molecular and General Genetics 185, 262-268.
Kolb, A., Spassky, A., Chapon, C., Blazy, B. \& Buc, H. (1983). On the different binding affinities of CRP at the lac, gal and malT promoter regions. Nucleic Acids Research 11, 7833-7852.

LAEMMLI, U. K. (1970). Cleavage of structural proteins during the assembly of the head of bacteriophage T4. Nature, London 227, 680685 .

LEVY, S., ZENG, G. Q. \& DANCHIN, A. (1990). cAMP synthesis in strains bearing well characterized deletions in the central pts genes of Escherichia coli. Gene 86, 27-33.

MaGaSanIK, B. (1970). Glucose effects: inducer exclusion and repression. In The Lactose Operon, pp. 189-219. Edited by J. Beckwith. Cold Spring Harbor, NY: Cold Spring Harbor Laboratory.

Manayan, R., Tenn, G., Yee, H. B., Desai, J. D., Yamada, M. \& SAIER, M. H., JR (1988). Genetic analyses of the mannitol permease of Escherichia coli: isolation and characterization of a transportdeficient mutant which retains phosphorylation activity. Journal of Bacteriology 170, 1290-1296.

MiLleR, J. H. (1972). Experiments in Molecular Genetics. Cold Spring Harbor, New York: Cold Spring Harbor Laboratory.

MORI, K. \& AIBA, H. (1985). Evidence for negative control of cya transcription by cAMP and cAMP receptor protein in intact Escherichia coli cells. Journal of Biological Chemistry 260, 1483814843.

PARDEE, A. B., JACOB, F. \& MONOD, J. (1959). The genetic control and cytoplasmic expression of inducibility in the synthesis of $\beta$ galactosidase of Escherichia coli. Journal of Molecular Biology 1, 165 178.

Phillips, J. H. \& Brown, D. M. (1967). The mutagenic action of hydroxylamine. Progress in Nucleic Acids Research and Molecular Biology 7, 349-368.

Postma, P. W. (1982). Regulation of sugar transport in Salmonella typhimurium. Annals of Microbiology 133A, 261-267.

Postma, P. W., Schuitema, A. \& KwA, C. (1981). Regulation of methyl- $\beta$-galactoside permease activity in pts and $\mathrm{cr}$ mutants of Salmonella typhimurium. Molecular and General Genetics 181, 448453.

Pottek, K., Chaloner-Larsson, G. \& Yamazaki, H. (1974). Abnormally high rate of cyclic AMP excretion from an Escherichia coli mutant deficient in cyclic AMP receptor protein. Biochemical and Biophysical Research Communications 57, 379-385.

Rambach, A. \& Hogness, D. S. (1977). Translation of Drosophilo melanogaster sequences in Escherichia coli. Proceedings of the National Academy of Sciences of the United States of America 74, 5041-5045.

RoY, A. \& DANCHIN, A. (1981). Restriction map of the cya region of the Escherichia coli $\mathrm{K} 12$ chromosome. Biochimie 63, 719-722.

RoY, A. \& DANChIN, A. (1982). The cya locus of Escherichia coli K 12: organization and gene products. Molecular and General Genetics 188, $465-471$.

Roy, A., Danchin, A., Joseph, E. \& Ullmann, A. (1983a). Two functional domains in adenylate cyclase of Escherichia coli. Journal of Molecular Biology 165, 197-202.

RoY, A., Haziza, C. \& DANCHIN, A. (1983b). Regulation of adenylate cyclase synthesis in Escherichia coli: nucleotide sequence of the control region. EMBO Journal 2, 791-797.

Roy, A., Glaser, P. \& Danchin, A. (1988). Aspects of the regulation of adenylate cyclase synthesis in Escherichia coli K12. Journal of General Microbiology 134, 359-367.

SANGER, F., NiCKLEN, S. \& COUlson, A. R. (1977). DNA sequencing with chain-terminating inhibitors. Proceedings of the National Academy of Sciences of the United States of America 74, 5463-5467.

Yanisch-Perron, C., Vieira, J. \& Messing, J. (1985). Improved M13 phage cloning vectors and host strains: nucleotide sequences of the M13mp18 and pUC19 vectors. Gene 33, 103-119.

ZubaY, G., SCHWARTZ, D. \& BECKWITH, J. (1970). Mechanism of activation of catabolite-sensitive genes: a positive control system. Proceedings of the National Academy of Sciences of the United States of America 66, 104-110. 